\title{
Influence of energy availability on \\ structure and function of anaerobic microbial communities
}

\author{
SUJUNG LIM ${ }^{1}$, RACHEL SZABO ${ }^{2}$, DAAN R. SPETH ${ }^{1}$, \\ OTTO X. CORDERO ${ }^{2}$ AND VICTORIA ORPHAN ${ }^{1}$ \\ ${ }^{1}$ Caltech \\ ${ }^{2}$ Massachusetts Institute of Technology \\ Presenting Author: lims@caltech.edu
}

In anaerobic, low-energy regimes, the redox potential of the terminal electron acceptor and the available electron donors drives the available free energy, and is predicted to impact the structure of microbial ecosystems. We examined the effect of energy availability on microbial community structure in controlled laboratory experiments using highly replicated 96well serial dilutions of deep-sea whalefall sediment under anoxic conditions, supplied with nitrate, iron oxide, sulfate, or no terminal electron acceptor. Incubations were also supplied with either chitin or its monomer $\mathrm{N}$-acetylglucosamine as the input electron donor. Through a combination of metagenomic sequencing, 16S rRNA gene amplicon sequencing, and geochemical analysis of major ions, we demonstrate a retention of functional redundancy of respiratory genes, a temporal shift in catabolism, and an energy-dependent response on microbial community structure as proxied through species richness maintained at high dilution levels. In active populations, soluble terminal electron acceptor (sulfate or nitrate) reduction is linked to the accumulation of downstream products, with deviations from the stoichiometric balance occurring over time. These experimental findings offer insight into how sediment microbial ecosystems may structure themselves according to availability and energetic yield of environmental electron acceptors, the role of functional redundancy in key processes such as sulfatereduction, and on the contribution of membership vs. metabolic guild to the net microbial community metabolism of complex organic matter. 